\title{
Regional Power Market Impact in Competitive Power Market: A Case Study in Zhejiang
}

\author{
DongFa Wang ${ }^{1}$, Weibin Ding ${ }^{1}$, Feng $\mathrm{Gao}^{1}$, Yang $\mathrm{Xu}^{2 *}$ and Yue $\mathrm{Fu}^{3}$ \\ ${ }^{1}$ State Grid Zhejiang Electric Power Co., Ltd., Hangzhou, Zhejiang, 310008, China \\ ${ }^{2}$ Economic Research Institute of State Grid Zhejiang Electric Power Co., Ltd., Hangzhou, Zhejiang, 310008, China \\ ${ }^{3}$ Jinhua Power Supply Company of State Grid Zhejiang Electric Power Co., Ltd., Jinhua, Zhejiang, 321000, China
}

\begin{abstract}
Along with the progress of the electricity market reform, the formulation of electricity prices and the bidding in the electricity market have become hot issues. Given that electricity price contains a variety of information in the electricity market and reflects market changes, insufficient understanding of electricity prices or improper response will not only affect the revenue of power supply companies, but also have adverse effects on consumers in the downstream of the electricity market. Taking Zhejiang Province as an example, this paper uses a Multi-objective optimization based on genetic algorithm to calculate the optimal power structure of Zhejiang Province under a competitive electricity market environment and evaluate the impact of the market. The results show that as the market reduces the transaction cost of purchased power, the purchased power to Zhejiang Province has a significant positive role in power cost, stability and cleanliness. The electricity cost could be cut down by 18.3 billion yuan, which is 0.04 yuan $/ \mathrm{kWh}$. In terms of cleanliness and stability of electricity consumption, the competitive electricity market will also bring about benefits by $2.43 \%$ and $1.64 \%$ respectively.
\end{abstract}

\section{Introduction}

Exploring the correlation between price and consumption in the electricity market is helpful to reveal the changing law of electricity price, which is an important signal of the market and an contributor to the formulation of bidding strategies for power plants[1, 2]. Establishing a competitive electricity market is also one of the goals of the new round of electricity system reform, while the wholesale power market is to further open up transmission services on the basis of the power generation competition, and is a method that allows big consumers and distribution utilities to participate in market competition. This transaction mode allows power generation companies to directly conduct transactions with distribution utilities and big consumer, greatly increasing the degree of competition in the power market $[3,4]$.

This paper uses a Multi-objective optimization based on genetic algorithm to calculate the optimal power structure of Zhejiang Province in a competitive electricity market. On this basis, this paper further measures the impact of the competitive market on the power system.

\subsection{Capacity and power generation status in Zhejiang province}

From the 13th Five-Year Plan for Zhejiang's power development, by 2020 , the power generation capacity is expected to reach about 94 million kilowatts, of which the thermal power, non-hydro renewable power, nuclear power, gas power, pumped storage, conventional hydropower and by-product heat and pressure power generation are $46.35,13.10,9.07,12.50,4.93,7.04$ and 1 million kilowatts respectively. According to the latest public data (Figure 1), thermal power still dominates, accounting for $74.4 \%$ in 2019 , higher than the national average $(69.6 \%)$, followed by nuclear power, accounting for $18.8 \%$. 


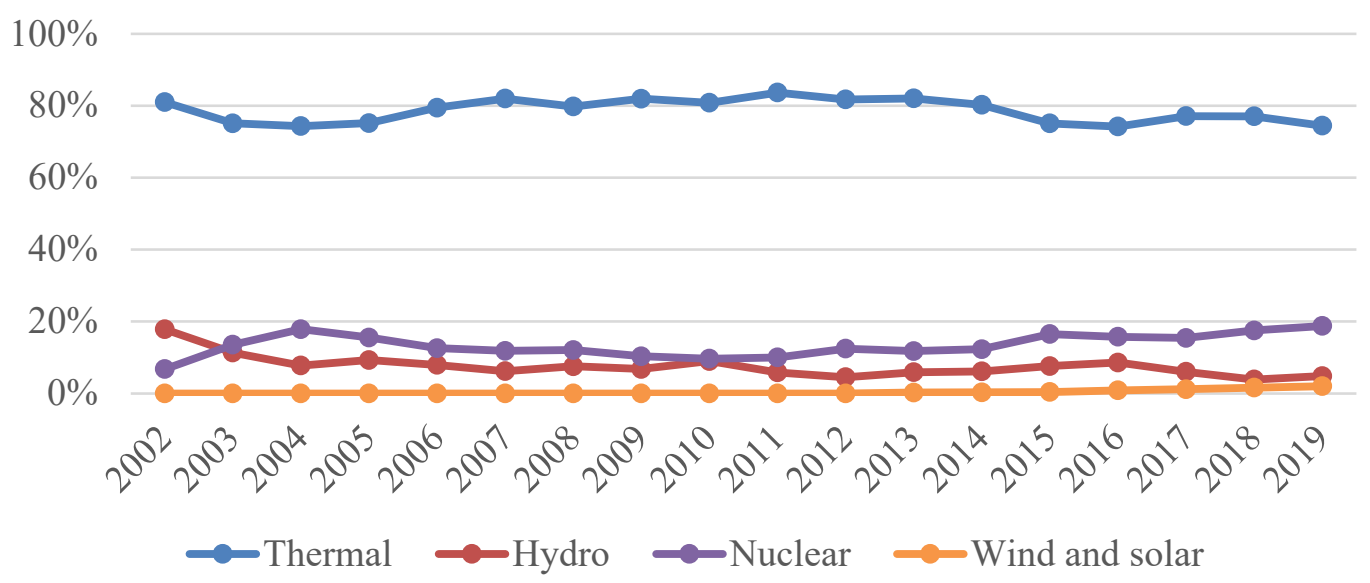

Figure 1. Power generation structure in Zhejiang Province (calculated by power generation).

According to the power balance plan of Zhejiang Province, in 2020, the province will arrange for 231.7 billion $\mathrm{kWh}$ of electricity generation, among which coalfired, natural gas, nuclear power and hydropower is planned as 191.1, 15-20, 22.6 and 3 billion $\mathrm{kWh}$ respectively, wind power, photovoltaic and local power plants are arranged to generate electricity as 63.7 billion $\mathrm{kWh}$.

\subsection{The purchased electricity in Zhejiang}

Zhejiang Province plans to purchase 160.5 billion $\mathrm{kWh}$ of electricity from other provinces in 2020, of which 32.6 billion $\mathrm{kWh}$ is from the Sanxia and Xiluodu hydropower station, 35.7 billion $\mathrm{kWh}$ is from East China Nuclear Power Plant, and these are arranged by the central government. The inter-governmental agreement arranged for 89.1 billion $\mathrm{kWh}$, arranging Eastern Ningxia coal-fired power units by $35-40$ billion $\mathrm{kWh}$, Anhui by 31.5 billion kWh, Sichuan hydropower by 6.6 billion kWh, Fujian by 3 billion kWh and Jiquan Direct current by 11.1 billion $\mathrm{kWh}$.

From the perspective of supply structure, the power purchased from Sanxia, Xiluodu and Sichuan are hydropower; the power purchased from Eastern Ningxia and Anhui is mostly thermal power; the power from Qinshan and Fujian is nuclear power; the power from Xinjiang is a bundle of multiple resources. According to the generation capacity of Xinjiang announced in April this year (the ratio of thermal: wind:solar power is approximately $6: 2: 1$ ), the power structure of Xinjiang's power supply to Zhejiang can be roughly estimated, and the power structure of Zhejiang Province planned for 2020 is shown in Table 1. The main transmission lines are shown in Table 2, and the upper limit of the purchased power generation/transmission capacity is shown in Table 3.

Table 1 Power structure (billion kWh, 2020).

\begin{tabular}{ccccccc}
\hline & Coal-fired & Natural gas & Nuclear & Hydro & Wind, solar, et al. & Total \\
\hline Generated & 191.1 & $15.0-20.0$ & 22.6 & 3.0 & 63.7 & $295.4-300.4$ \\
Purchased & 78.9 & & 38.7 & 39.2 & 37.0 & 160.5 \\
Total & 270.0 & $15.0-20.0$ & 61.3 & 42.2 & 67.4 & $455.9-460.9$ \\
\hline
\end{tabular}

Table 2 Main transmission lines of purchased power.

\begin{tabular}{ll}
\hline Source & Transmission Line \\
\hline Sanxia and Xiluodu & $\pm 800 \mathrm{KV}$ Binjin Direct current \\
Qinshan Nuclear (Fangshan) & $500 \mathrm{KV}$ high voltage transmission lines \\
Eastern Ningxia & $\pm 800 \mathrm{KV}$ Lingshao Direct current \\
Anhui & $1000 \mathrm{KV}$ high voltage transmission lines \\
Sichuan Hydro & $\pm 800 \mathrm{KV}$ Yangzhong Direct current \\
Xinjiang & $\pm 1100 \mathrm{KV}$ high voltage transmission lines \\
Fujian & $1000 \mathrm{KV}$ high voltage transmission lines \\
\hline
\end{tabular}

Table 3 Upper limit of the purchased power generation/transmission capacity (billion kWh).

\begin{tabular}{lll}
\hline Source & Upper limit & Method \\
\hline Sanxia and Xiluodu & 28.5 (Planned Volume to & $\begin{array}{l}\text { Xiluodu has an annual generation of 57.1 billion kWh, of which 50\% is } \\
\text { transmitted to Guangdong and 50\% to Zhejiang. }\end{array}$ \\
Zinshan Nuclear & 51.7 (Total generation) & $\begin{array}{l}\text { In 2019, the 9 units of Qinshan Nuclear Power generated a total of 51.778 } \\
\text { (Fangshan) }\end{array}$
\end{tabular}




\begin{tabular}{ll} 
Eastern Ningxia & $\begin{array}{l}50.0 \text { (Transmission line } \\
\text { restriction) } \\
50.0 \text { (Transmission line } \\
\text { Anhui }\end{array}$ \\
restriction) \\
16.2 (Surplus hydropower) \\
Sichuan Hydro & 71.2 (Total delivery) \\
Xinjiang & 43.5 (Total generation of \\
Fujian & nuclear) \\
\hline
\end{tabular}

\section{Electricity Cost Accounting in Zhejiang Province}

\subsection{Generating side electricity price accounting}

The generating side electricity prices calculated from the power supply provinces reflect the generation cost of power sources, and then play a guiding role in the formation of future electricity market-oriented transaction prices. According to the latest electricity price supervision report "2018 National Electricity Price Regulatory Bulletin", the generating side prices are sorted out in Table 4 by various sources.

Table 4 Generating side prices sorted by sources (yuan $/ \mathrm{kWh}$ ).

\begin{tabular}{lll}
\hline Type & Source & Price in 2018 \\
\hline Generated & Coal & 0.4163 \\
& Nuclear & 0.9321 \\
& Natural gas & 0.4250 \\
& Hydro & 0.5668 \\
& Wind & 0.7334 \\
& Solar & 1.1336
\end{tabular}

Lingshao $\pm 800 \mathrm{kV}$ DC allows for 50 billion $\mathrm{kWh}$ of annual electricity transmission.

The power transmission from Anhui to Zhejiang allows for an annual ransmission of 50 billion $\mathrm{kWh}$.

In 2019, Sichuan "abandoned water" power was 9.2 billion kWh, and power transmitted to Zhejiang was 7 billion $\mathrm{kWh}$

Power Transmission from Xinjiang was of 71.2 billion kWh in 2019

The capacity is 8.71 million $\mathrm{kW}$, with an average annual operating hours of 5000 hours.

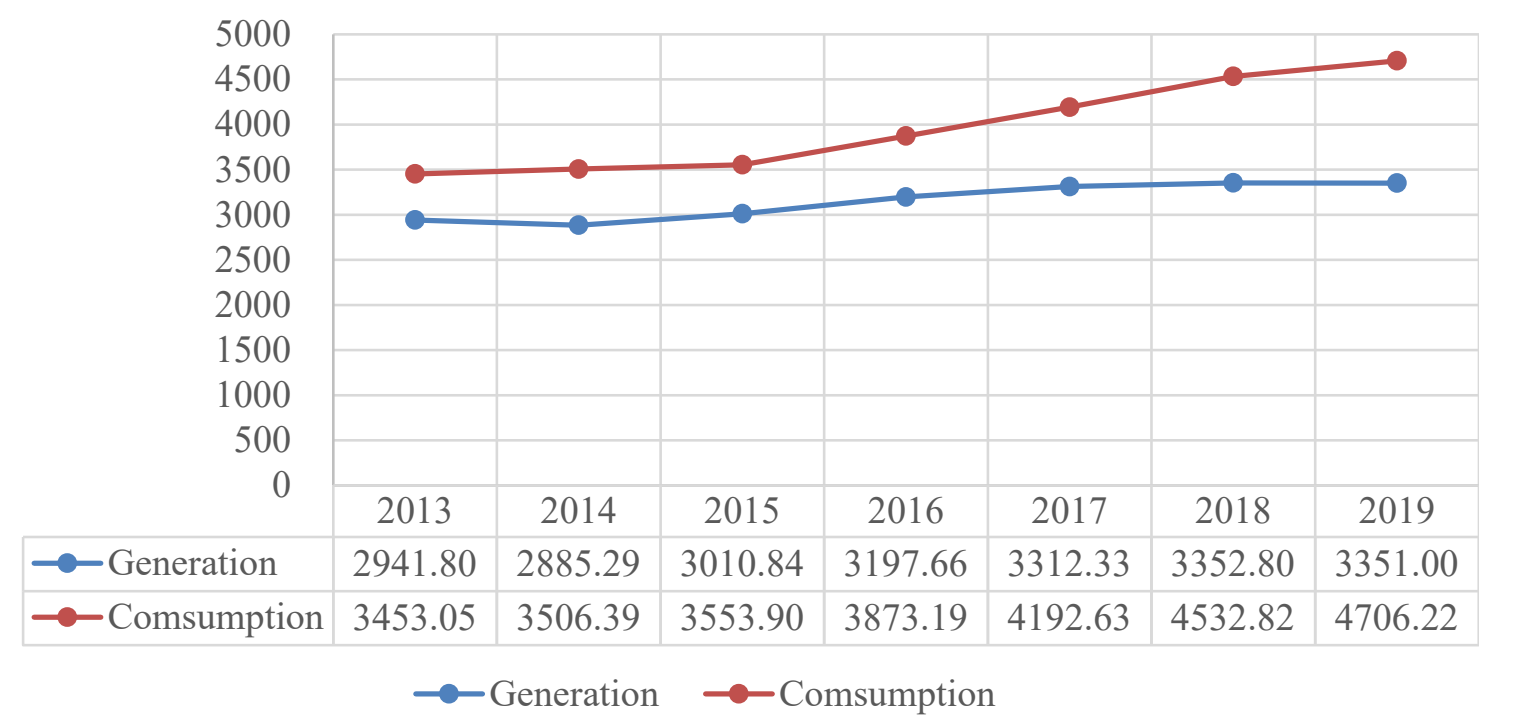

Figure 2. The power generation and consumption in Zhejiang Province.

From the perspective of electricity consumption structure (see Figure 3), in 2019, the proportions of electricity consumption by the primary, secondary and tertiary industries and residents were $0.44 \%, 70.71 \%$, $15.23 \%$ and $13.62 \%$, respectively, and the growth of electricity consumption was respectively $-1.53 \%, 2.59 \%$,

\begin{tabular}{lll} 
Purchased & Hydro (Sanxia and Xiluodu) $^{\mathrm{a}}$ & 0.2783 \\
& Qinshan (Fangshan) & 0.3005 \\
Anhui & 0.3828 \\
Eastern Ningxia & 0.2487 \\
Sichuan hydro $^{\text {Xinjiang }}{ }^{\mathrm{b}}$ & 0.2800 \\
Fujian & 0.3424 \\
\hline
\end{tabular}

a. As Xiluodu and Qinshan are national unified dispatching power plants, the prices are determined according to the tax-included generating side electricity price sent to Zhejiang in 2019

b. The price for electricity purchased from Xinjiang is calculated according to the weight of thermal, wind, and solar capacity, which is $6: 2: 1$

\subsection{Electricity demand forecast}

According to the data in recent years, the electricity consumption in Zhejiang Province has been increasing year by year, but the power generation is relatively stable, and there is a trend of increasing gap between consumption and generation, as is shown in Figure 2. 


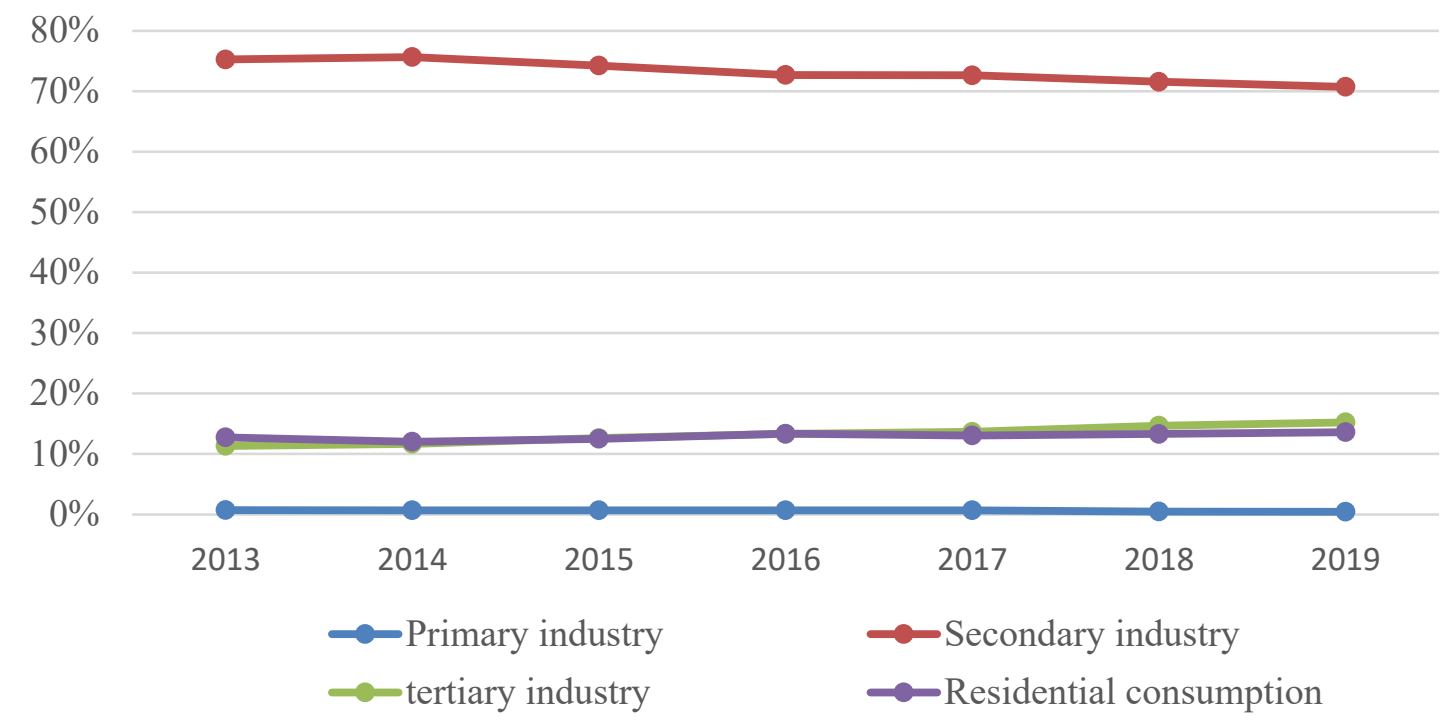

Figure 3. Electricity consumption structure in Zhejiang Province.

In 2019, GDP in Zhejiang actually increased by about $6.8 \%$, and electricity consumption increased by $3.82 \%$. With the GDP growth target of $6 \%-6.5 \%$, in accordance with the electricity supply and consumption situation in the first quarter, it is estimated that the electricity consumption of the whole society will increase by $0 \%-1.5 \%$ for the year 2020 under normal climatic conditions, and the electricity consumption of will be $470.6-477.7$ billion $\mathrm{kWh}$, the maximum load is about 91 million $\mathrm{kW}$, with an increase of $6.9 \%$.

From the perspective of power supply, the implementation of purchased power resources this year is relatively good, but the province's new installed capacity is insufficient, and the controlled coal constraints will affect the power generation of coal-fired units in the province and the Yangtze River Delta. In general, the power balance in peak season will be tightened this summer, and there will still be a certain gap. In the event of extreme weather, there may be a gap in power supply and demand.

\section{Optimal power structure model of Zhejiang province considering extraneous electricity shock}

\subsection{Multi-objective optimization model}

In this part, we try to use the multi-objective optimization model to analyze the optimal power structure of Zhejiang province in the case of a perfect competition power market in the future. The core issues to be addressed in this paper are shown in figure 4.

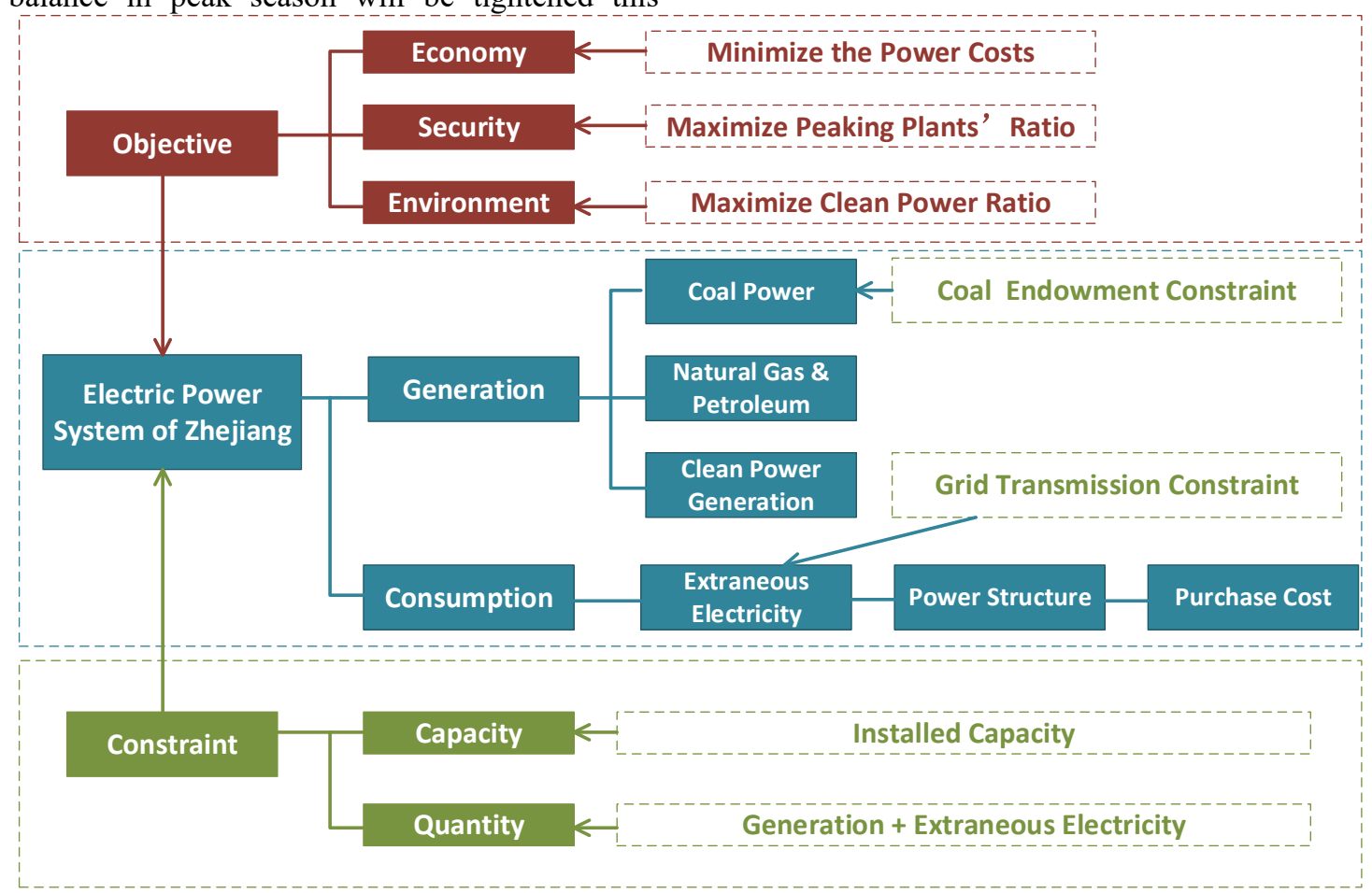

Figure 4. Multi-objective optimization problem. 
A multi-objective optimization problem refers to the problem with two or more objectives. For Zhejiang province's power system, the goal to be achieved could be described from three dimensions. The first is economy, that is, under the condition of the entire competition power market, the power source can choose to produce within the province and purchase power externally. The primary goal is to minimize the cost of electricity consumption, and the competitive power market also provides a foundation for the realization of this goal. The purpose of the second dimension is safety. Thermal power units have a strong peak regulating capacity, stable supply, and high-power quality (Anuj et al, 2017; Usama et al, 2016). To maintain the safety and stability of Zhejiang's electric power system, it is necessary to maximize the proportion of adjustable peak thermal power produced in Zhejiang province. The third-dimension target is the environment, which becomes increasingly polluted as the economy improves. Zhejiang has always been the province with the most emphasis on environmental protection, the strictest environmental protection standards, and the complete ecological monitoring. Therefore, the goal of the third dimension requires that the proportion of clean energy electricity be as high as possible.

From the perspective of constraints, the most important limitation is the electricity constraint, that is, the sum of the generated and extraneous electricity should meet the primary electricity demand of Zhejiang province. In terms of other restrictions, self-generated thermal power within the province should meet the constraints of coal resource endowment (including transportation conditions), and the extraneous electricity quantity should meet the limit constraint of network planning channel capacity.

The optimal power structure model of Zhejiang province adopted in this paper can be expressed in the following formula.

Object:

$\min \sum_{i=1}^{10} P_{i} * X_{i}$

$\max \left(X_{1}+X_{2}\right) / \sum_{i=1}^{10} X_{i}$

$\max \left(X_{3}+X_{4}+X_{5}+X_{8}+X_{9} / 3+X_{10}\right) / \sum_{i=1}^{10} X_{i}$

Subject to:

$a * X_{1} \leq b$

$X_{i} \leq c_{i}, i=4,5, \cdots, 10$

$\sum_{i=1}^{10} X_{i} \geq d$

$X_{i} \leq e_{i}, i=1,2,3$

Among them, $X_{1}, X_{2}$ and $X_{3}$ respectively represent the generation of coal power, natural gas and clean energy in Zhejiang province. $X_{4}, X_{5}, X_{6}, X_{7}, X_{8}, X_{9}$ and $X_{10}$ are the purchased electricity quantities from different sources, which respectively represent the three Gorges Project, Xiluodu trans-regional hydropower Station, East
China Unified nuclear Power Station, Anhui Power Station, Ningdong Power Station, Zhejiang Coal Power Station, Sichuan Hydropower Station, Jiquan Direct Current power Station, and Fujian Nuclear Power Station summarized above. And $P_{i}$ corresponds to the price of each power source. $a$ is Zhejiang province's average coal power generation efficiency, and $b$ represents for coal resources endowment. Formula (5) is to express the electricity transmission constraints, and $c_{i}$ is the corresponding measure of the power grid. Formula (6) expresses the electric quantity constraint, and the sum of production and purchased electric quantity is not less than the electricity demand. Formula (7) represents the installed constraint of self-generated electricity, that is, the power generation within the province cannot exceed the installed power generation at full load. By solving this problem, the optimal power structure of Zhejiang province can be estimated under the condition of perfect power market competition.

\subsection{Multi-objective optimization based on genetic algorithm}

The essence of the traditional multi-objective optimization method is to transform each sub-objective function into a single objective function after processing or mathematical transformation. And then solve the problem by using single-objective optimization technology[5]. A multiobjective optimization algorithm can find the most reasonable and reliable solution from all possible solutions. Traditional multi-objective optimization methods include the evaluation function method, interactive programming method, and hierarchical solution method.

Genetic algorithm (GA) can simultaneously search a large number of feasible solutions in the whole space in parallel, overcoming the dilemma that traditional methods may converge to local optimal[6]. Using GA to solve the practical solution set of the multi-objective optimization problem is an effective means[7].

According to Knowles \& Corne[8], the main steps of the underlying genetic algorithm adopted in this paper are shown in figure 5. Firstly, an initial population with a certain length is randomly generated. Secondly, the iteration of the string population is performed to calculate the adaptive value, and chromosome replication, crossover, and mutation are performed to produce the next generation population. Next, the best individual string that occurs in any generation is specified as the result of the algorithm's execution. Finally, after a given genetic algebra, all the execution results are compared to obtain the optimal one as the solution to the optimization process. 


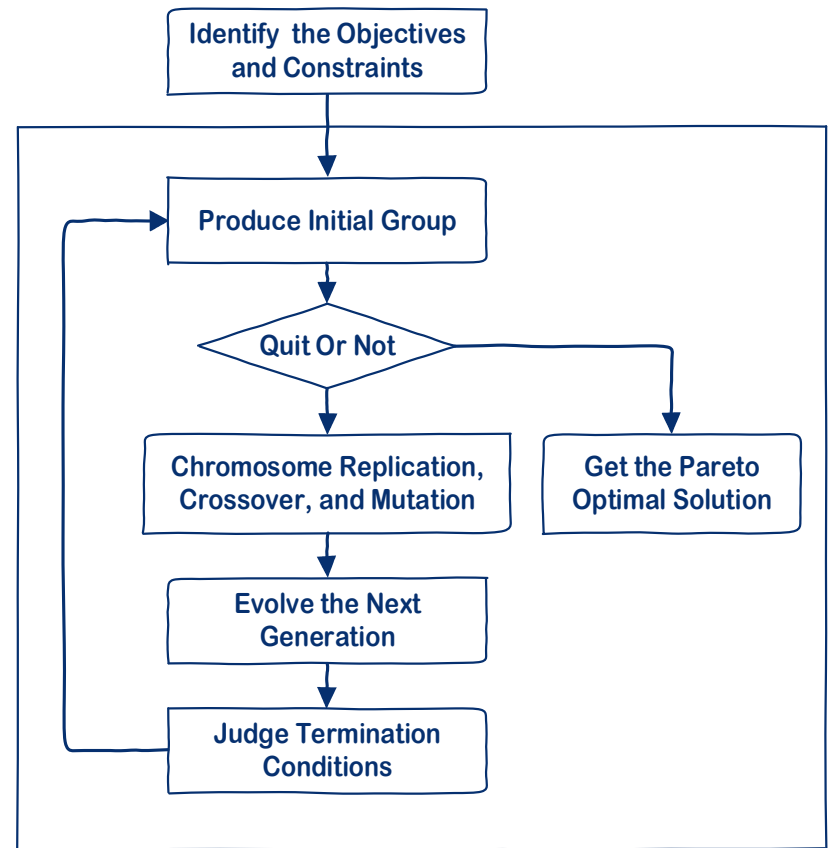

Figure 5. A genetic algorithm for optimizing multi-objective problem

\subsection{Multi-objective optimization model}

As mentioned above, the specific set of model parameters in this paper is shown in table 5 .

Table 5. Model parameter setting

\begin{tabular}{|c|c|c|c|c|c|}
\hline Symbol & Implication & Value & Symbol & Implication & Value \\
\hline$P_{1}$ & Coal & 0.4163 yuan/ KWh & $d$ & Power demand & $480 \mathrm{GWh}$ \\
\hline$P_{2}$ & Gas & 0.4250 yuan/ KWh & $c_{4}$ & $\begin{array}{c}\text { Trans-regional } \\
\text { hydropower }\end{array}$ & $28.5 \mathrm{GWh}$ \\
\hline$P_{3}$ & Clean enery & 0.8636 yuan/ KWh & $c_{5}$ & $\begin{array}{c}\text { East China nuclear } \\
\text { power }\end{array}$ & $51.7 \mathrm{GWh}$ \\
\hline$P_{4}$ & Trans-regional hydropower & 0.2783 yuan/ KWh & $c_{6}$ & Anhui electricity & $50 \mathrm{GWh}$ \\
\hline$P_{5}$ & East China nuclear power & 0.3005 yuan/ KWh & $c_{7}$ & Ningdong Power & $50 \mathrm{GWh}$ \\
\hline$P_{6}$ & Anhui electricity & 0.3828 yuan/ KWh & $c_{8}$ & Sichuan Hydropower & $16.2 \mathrm{GWh}$ \\
\hline$P_{7}$ & Ningdong Power & 0.2487 yuan/ KWh & $c_{9}$ & Jiquan power & $71.2 \mathrm{GWh}$ \\
\hline$P_{8}$ & Sichuan Hydropower & 0.2800 yuan/ KWh & $c_{10}$ & Fujian Nuclear Power & $43.5 \mathrm{GWh}$ \\
\hline$P_{9}$ & Jiquan power & 0.3424 yuan/ KWh & $e_{1}$ & Coal capacity & $46.35 \mathrm{MW}$ \\
\hline$P_{10}$ & Fujian Nuclear Power & 0.3725 yuan/ KWh & $e_{2}$ & Gas capacity & $12.5 \mathrm{MW}$ \\
\hline$a$ & Coal power efficiency & 296.50 Gram/ KWh & $e_{3}$ & Clean capacity & $29.64 \mathrm{MW}$ \\
\hline$b$ & Coal consumption & 74 million tons & & & \\
\hline
\end{tabular}

The multi-objective optimization model based on genetic algorithm was calculated by R 4.0.2 software. The optimal power structure of Zhejiang province under the

Table 6. Optimal power structure in Zhejiang province under competitive power market environment (GWh)

\begin{tabular}{|c|c|c|c|c|c|}
\hline & Power Source & Optimal Power & $\begin{array}{c}\text { proportion of } \\
\text { electricity }\end{array}$ & $\begin{array}{c}\text { Planning } \\
\text { power }\end{array}$ & $\begin{array}{c}\text { proportion of } \\
\text { electricity }\end{array}$ \\
\hline \multirow[t]{3}{*}{$\begin{array}{c}\text { Internal } \\
\text { generation }\end{array}$} & Coal & 221.9 & $46.21 \%$ & 191.1 & $41.92 \%$ \\
\hline & Gas & 5.6 & $1.17 \%$ & 17.5 & $3.84 \%$ \\
\hline & Clean enery & 48.3 & $10.06 \%$ & 89.3 & $19.59 \%$ \\
\hline \multirow[t]{6}{*}{$\begin{array}{l}\text { Extraneous } \\
\text { electricity }\end{array}$} & Trans-regional hydropower & 12.8 & $2.67 \%$ & 32.6 & $7.15 \%$ \\
\hline & East China nuclear power & 55.8 & $11.62 \%$ & 35.7 & $7.83 \%$ \\
\hline & Anhui electricity & 49.5 & $10.31 \%$ & 31.5 & $6.91 \%$ \\
\hline & Ningdong Power & 3.8 & $0.79 \%$ & 37.5 & $8.23 \%$ \\
\hline & Sichuan Hydropower & 11.5 & $2.39 \%$ & 6.6 & $1.45 \%$ \\
\hline & Jiquan power & 46 & $9.58 \%$ & 11.1 & $2.43 \%$ \\
\hline
\end{tabular}

competitive power market environment is shown in table 6. 


\begin{tabular}{|c|c|c|c|c|c|}
\hline & Fujian Nuclear Power & 25 & $5.21 \%$ & 3 & $0.66 \%$ \\
\hline Total & & 480 & & 455.9 & \\
\hline
\end{tabular}

As can be seen from the calculation results, under the competitive power market environment, the proportion of coal power in Zhejiang province will increase slightly, and the percentage of clean energy generation will decrease, and external power will be purchased. In particular, external clean energy electricity, which is also a major change after extraneous electricity entered the market competition. In terms of the proportion of extraneous electricity, planning purchased electricity of Zhejiang province only accounts for $34.66 \%$. In contrast, in the optimal power structure under perfect competition, the ratio reaches $42.57 \%$, an increase of nearly eight percentage points. The purchased clean electricity increased significantly. Under the original plan, the total purchased clean electricity was $89 \mathrm{GWh}$, while in the optimal structure, the purchased clean electricity exceeded $150 \mathrm{GWh}$. This is mainly because of the clean power generation in Zhejiang province comes mostly from nuclear power, and the cost is relatively high. Low-cost hydropower accounts for a relatively high proportion of outsourced clean electricity, so the enhancement of electricity market competitiveness provides a basis for cost-saving and electricity cleaning.

Furthermore, we investigate the changes in electricity cost of Zhejiang province under the competitive power market environment, and the calculation results are shown in table 7.

Table 7. Evaluation of the competitive power market impact

\begin{tabular}{|c|c|c|c|c|c|}
\hline Indicator & Optimal Power & Planning power & $\begin{array}{c}\text { Adjusted planning } \\
\text { power }\end{array}$ & Impact 1 & Impact 2 \\
\hline Cost (billion yuan) & 204.99 & 212.067 & 223.30 & -7.09 & -18.32 \\
\hline Clean (\%) & $41.54 \%$ & $39.11 \%$ & $39.11 \%$ & $2.43 \%$ & $2.43 \%$ \\
\hline Stability (\%) & $47.40 \%$ & $45.76 \%$ & $45.76 \%$ & $1.64 \%$ & $1.64 \%$ \\
\hline
\end{tabular}

The second column in the table is the calculated optimal power structure, and the third column is the initially planned power quantity. The total amount of planned power initially is about $455.9 \mathrm{GWh}$, which cannot meet the 480 GWh primary power demand of Zhejiang province. Therefore, it is adjusted from the original structure, and the specific values are shown in the fourth column of table 7 .

As can be seen from the results in the table, when the power market is in a perfect competition environment, it will bring three benefits to the power system of Zhejiang province. First, the cost of electricity is the most straightforward. Compared with the original plan, the electricity cost could be saved by about 18.3 billion yuan. Calculated according to per $\mathrm{KWh}$, under the optimal structure, the cost is 0.4270 yuan/KWh, while under the planning, the cost is 0.4652 yuan/KWh. Therefore, the competitive power market will lead to a lower transaction cost of extraneous electricity, which will bring a reduction of 18.3 billion yuan of electricity cost in Zhejiang province and saving of 0.04 yuan per KWh. Moreover, in terms of electricity cleanliness and stability, the competitive electricity market will bring $2.43 \%$ and $1.64 \%$ improvement, respectively.

\section{Conclusions and policy recommendations}

Taking Zhejiang province as an example, this paper uses the multi-objective optimization model based on genetic algorithm to calculate the optimal power structure under the competitive power market environment. Compared with the original plan, the proportion of coal power generation in the province has been slightly increased, while clean energy generation has been slightly decreased. However, the proportion of purchased electricity increased significantly. In the original plan, the proportion of purchased electricity was only $34.66 \%$, while in the optimal power structure under perfect competition, the proportion of purchased electricity reached $42.57 \%$, an increase of nearly eight percentage points. In particular, the proportion of extraneous clean electricity significantly increased.

However, the proportion of clean energy generation will decrease, and extraneous power will be purchased. In particular, external clean energy electricity, which is also a major change after extraneous electricity entered the market competition. In terms of the proportion of extraneous electricity, planning purchased electricity of Zhejiang province only accounts for $34.66 \%$, while in the optimal power structure under perfect competition, the ratio reaches $42.57 \%$, an increase of nearly eight percentage points. Under the original plan, the total purchased clean electricity was $89 \mathrm{GWh}$, while the purchased clean electricity in the optimal structure exceeded $150 \mathrm{GWh}$. This is mainly because of the clean power generation in Zhejiang province mainly comes from nuclear power, and the cost is relatively high. Furthermore, we investigate the changes of electricity cost of Zhejiang province under the competitive power market environment. From the results, we can see that the competitive power market environment directly reduces the transaction cost of purchased electricity $[9,10]$. As a result, it has a significant positive effect to Zhejiang power system in terms of electricity cost, electricity stability, and cleanliness. Firstly, it will bring a reduction of 18.3 billion yuan of electricity cost in Zhejiang province and saving of 
0.04 yuan per KWh. Moreover, in terms of electricity cleanliness and stability, the competitive electricity market will bring $2.43 \%$ and $1.64 \%$ improvement, respectively.

\section{Acknowledgments}

The authors would like to thank the support of the project: The settlement mechanism optimization strategy under the deepening of power reform (Grant: JY02202027)

\section{References}

1. Subhojit Dawn, Prashant Kumar Tiwari, Arup Kumar Goswami. An approach for long term economic operations of competitive power market by optimal combined scheduling of wind turbines and FACTS controllers[J]. Energy,2019,181.

2. Prashant Kumar Tiwari, Manash Kumar Mishra, Subhojit Dawn. A two step approach for improvement of economic profit and emission with congestion management in hybrid competitive power market[J]. International Journal of Electrical Power and Energy Systems,2019,110.

3. Priyanka Singh, Pragya Dwivedi. Integration of new evolutionary approach with artificial neural network for solving short term load forecast problem[J]. Applied Energy,2018,217.

4. Subhojit Dawn, Prashant Kumar Tiwari, Arup Kumar Goswami. An approach for efficient assessment of the performance of double auction competitive power market under variable imbalance cost due to high uncertain wind penetration[J]. Renewable Energy,2017,108.

5. Schaffer J D. Multiple Objective Optimization with Vector Evaluated Genetic Algorithms[C], International Conference on Genetic Algorithms. Lawrence Erlbaum Associates Publishers, Hillsdale, 1985.

6. Guliashki, Vassil, Toshev, Hristo, Korsemov, Chavdar. Survey of Evolutionary Algorithms used in multiobjective optimization[J]. Problemi Tekhn.kibernet.robot, 2008, 60:42-54.

7. Irena Milstein, Asher Tishler. Can price volatility enhance market power? The case of renewable technologies in competitive electricity markets[J]. Resource and Energy Economics,2015,41.

8. Knowles J D , Corne D W . Approximating the Nondominated Front Using the Pareto Archived Evolution Strategy[J]. Evolutionary Computation, 2014, 8(2):149-172.

9. Ali Nazemi, Mehdi Mashayekhi. Competitiveness assessment of Iran's restructured electricity market[J]. Energy Economics,2015,49.

10. João Lagarto, Jorge A.M. Sousa, Álvaro Martins, Paulo Ferrão. Market power analysis in the Iberian electricity market using a conjectural variations model[J]. Energy,2014,76. 